\title{
Need to identify the risk factor for stone recurrence after common bile duct exploration
}

\author{
Kee-Hwan Kim \\ Division of Hepato-Pancreato-Biliary Surgery, Department of Surgery, Uijeongbu St. Mary's Hospital, College of Medicine, The Catholic University of \\ Korea, Seoul, Korea
}

\begin{abstract}
Choledocholithiasis and cholecystitis are among the most common surgical conditions in the hepatopancreato-biliary section. The recurrence of common bile duct (CBD) stones is considered an unsolved problem after cholecystectomy. In the setting of recurrent CBD stones, the management approach is regular follow-up after surgery in patients with the risk factors of recurrence. Many contributing factors also predispose the patient to the formation of recurrent primary CBD stones. Therefore, it is essential to evaluate the more influential risk factors and their role in predicting the occurrence of $\mathrm{CBD}$ stones.
\end{abstract}

Keywords: Common bile duct, Choledocholithiasis, Risk factors, Leukocytosis

\author{
Received March 10, 2021 \\ Revised March 12, 2021 \\ Accepted March 13, 2021 \\ Corresponding author \\ Kee-Hwan Kim \\ Division of Hepato-Pancreato-Biliary \\ Surgery, Department of Surgery, \\ The Catholic University of Korea, \\ Uijeongbu St. Mary's Hospital, 271 \\ Cheonbo-ro, Uijeongbu 11765, Korea \\ Tel: +82-31-820-3562 \\ Fax: +82-31-847-2717 \\ E-mail: keehwan@catholic.ac.kr \\ ORCID: \\ https://orcid.org/0000-0001-6219-6027
}

Copyright () 2021 The Journal of Minimally Invasive Surgery. All rights reserved.
This is an Open Access article distributed under the terms of the Creative Commons Attribution Non-Commercial License (http:// creativecommons.org/licenses/by-nc/4.0/) which permits unrestricted non-commercial use, distribution, and reproduction in any medium, provided the original work is properly cited.
Between $10 \%$ and $18 \%$ of people undergoing cholecystectomy for gallstones have common bile duct (CBD) stones. Bile duct stones can be treated by open cholecystectomy plus an open CBD exploration or laparoscopic cholecystectomy plus laparoscopic CBD exploration. On the other hand, the stones can be treated with pre- or postcholecystectomy endoscopic retrograde cholangiopancreatography (ERCP) in two stages, usually combined with either endoscopic sphincterotomy (EST) or sphincteroplasty (papillary dilatation) for CBD clearance. The benefits and harm of the different approaches are not known [1].

Generally, the recurrence rate of CBD stone has been quoted in the literature as between $4 \%$ and 25\% [2-6]. Nevertheless, CBD stone recurrence is considered an unpredictable problem after cholecystectomy. Several trials have investigated CBD stone re- currence after ERCP with EST, but it is insufficient to explain $\mathrm{CBD}$ stone recurrence after cholecystectomy. Yoo et al. [7] reported CBD stone recurrence factor that the CBD stone number $(\geq 2)$, presence of cholesterol stones, and sharp bile duct angulation $\left(<145^{\circ}\right)$ were associated with CBD stone recurrence after cholecystectomy, while the presence of the periampullary diverticulum (PAD) was not. In contrast, Oak et al. [8] reported that the risk factors for CBD stone recurrence after cholecystectomy were the presence of type I or II PAD and multiple CBD stones. The data result about $\mathrm{CBD}$ stone recurrence risk factors can be confusing. Basically, the CBD stone recurrence risk factor may predispose a patient to bile stasis and promote stone formation. Stasis is believed to play an important role in the pathogenesis of cholesterol gallbladder stone for retention of cholesterol su- 
persaturated bile in the gallbladder long enough to provide time for nucleation and precipitation of cholesterol crystals and retention of crystals to allow them to grow into stones. Ekici et al. [9] demonstrated that patients with leukocytosis have an increased rate of conversion to open cholecystectomy during laparoscopic cholecystectomy.

In the article of Choi et al. [10] in this issue of Journal of Minimally Invasive Surgery, the author concluded that 'the preoperative white blood cell count elevation could be associated with recurrent choledocholithiasis.' Worsening leukocytosis is a more universal sign of systemic inflammation and infection; however, its role in predicting $\mathrm{CBD}$ stone occurrence in the setting of the risk factors for postoperative CBD stones has not been established. Therefore, further study with a larger sample size will be needed to reach more definitive conclusions.

\section{NOTES}

\section{Conflict of interest}

The author has no conflicts of interest to declare.

\section{REFERENCES}

1. Dasari BV, Tan CJ, Gurusamy KS, et al. Surgical versus endoscopic treatment of bile duct stones. Cochrane Database Syst Rev 2013;(9): CD003327.

2. Prat F, Malak NA, Pelletier G, et al. Biliary symptoms and complications more than 8 years after endoscopic sphincterotomy for cho- ledocholithiasis. Gastroenterology 1996;110:894-899.

3. Freeman ML, Nelson DB, Sherman S, et al. Complications of endoscopic biliary sphincterotomy. N Engl J Med 1996;335:909-918.

4. Kim KY, Han J, Kim HG, et al. Late complications and stone recurrence rates after bile duct stone removal by endoscopic sphincterotomy and large balloon dilation are similar to those after endoscopic sphincterotomy alone. Clin Endosc 2013;46:637-642.

5. Sugiyama M, Atomi Y. Risk factors predictive of late complications after endoscopic sphincterotomy for bile duct stones: long-term (more than 10 years) follow-up study. Am J Gastroenterol 2002;97:27632767.

6. Costi R, Mazzeo A, Tartamella F, Manceau C, Vacher B, Valverde A. Cholecystocholedocholithiasis: a case-control study comparing the short- and long-term outcomes for a "laparoscopy-first" attitude with the outcome for sequential treatment (systematic endoscopic sphincterotomy followed by laparoscopic cholecystectomy). Surg Endosc 2010;24:51-62.

7. Yoo ES, Yoo BM, Kim JH, et al. Evaluation of risk factors for recurrent primary common bile duct stone in patients with cholecystectomy. Scand J Gastroenterol 2018;53:466-470.

8. Oak JH, Paik CN, Chung WC, Lee KM, Yang JM. Risk factors for recurrence of symptomatic common bile duct stones after cholecystectomy. Gastroenterol Res Pract 2012;2012:417821.

9. Ekici U, Tatlı F, Kanlı̈z M. Preoperative and postoperative risk factors in laparoscopic cholecystectomy converted to open surgery. Adv Clin Exp Med 2019;28:857-860.

10. Choi HW, Min SK, Lee HK, Lee H. Risk factors of recurrence following common bile duct exploration for choledocholithiasis. J Minim Invasive Surg 2021;24:43-50. 